\title{
(Mere) Verbalness and Substantivity Revisited
}

\author{
Viktoria Knoll ${ }^{1}$
}

Received: 10 February 2020 / Accepted: 30 May 2021

(c) The Author(s) 2021

\begin{abstract}
Verbal disputes are often seen as closely related to a lack of substantivity. However, a systematic and comprehensive investigation of how verbalness relates to substantivity is still missing. The present paper attempts to close this gap. In addition to offering different conceptions of verbalness, the paper further develops Sider's (Writing the Book of the World, OUP, Oxford, 2011) notion of substantivity. Ultimately, I argue for a more careful choice of terminology when it comes to assessing a dispute as "(merely) verbal" or "nonsubstantive". While the paper shows that there is no strict logical relation between mere verbalness and nonsubstantivity construed along the lines set out by Sider, it also demonstrates that further notable notions of (mere) verbalness and substantivity are in fact closely intertwined.
\end{abstract}

\section{Introduction}

Consider the following dispute:

Anna: "One billion is $10^{6}$."

Ben: "I disagree, Anna. One billion is not $10^{6}$."

Assume that Anna, who is German, is confused about the meaning of English number terms. She remembers hearing her English teacher say that the English term "billion" is not synonymous with the German "Billion". Yet, unfortunately, Anna now uses the English "billion" synonymously with the English "million". Hence, by

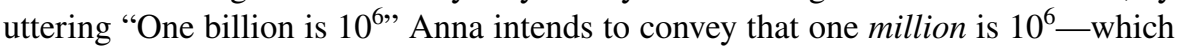
is correct. Only by mistake she uses "billion" with speaker's meaning [million]. ${ }^{1}$ Ben, on the other hand, uses "billion" to refer to $10^{9}$. Assume further that the two speakers agree on all mathematical facts relevant to their dispute- the fact that one million is $10^{6}$ as well as the fact that one billion is not $10^{6}$. They merely present the

\footnotetext{
1 (Possible) meanings are marked by square brackets throughout this paper.

Viktoria Knoll

viktoria.knoll@tu-dresden.de

1 TU Dresden, Institute of Philosophy, Zellescher Weg 17, 01062 Dresden, Germany
} 
appearance of disagreement due to their divergent uses of "billion", 2 and are thus having what many philosophers (like e.g. Balcerak Jackson (2014), Jenkins (2014), Vermeulen (2018) or Belleri (2018)) would describe as a paradigmatic example of a merely verbal dispute. Although there is some controversy about the exact nature of such disputes, it seems fair to say that there is widespread agreement about two conditions: in a merely verbal dispute (i) there is no relevant disagreement between the disputants on the subject matter(s) under discussion, but (ii) the disputants use at least one key expression of their dispute differently. In this sense, speakers in a merely verbal dispute are merely talking past each other. ${ }^{3}$

Note that what matters for mere verbalness is pragmatics, not semantics. A merely verbal dispute arises in a certain context because speakers are using a key expression $(e)$ of their dispute differently, i.e. with different speaker's meaning. ${ }^{4}$ Hence "speaker's meaning is the fundamental explanatory notion" (Vermeulen, 2018 , p. 346) in an account of mere verbalness. It is understood in a broadly Gricean fashion (cf. Grice, e.g. 1957, 1969): the speaker's meaning of $e$ uttered by a speaker $s$ in a certain context $c$ is what $s$ intends to convey by uttering $e$ in $c .^{5}$ This way the speaker's meaning of $e$ can-but does not have to-diverge from the linguistic meaning of $e$ (cf. Anna's use of "billion”).

With speakers often displaying a certain amount of linguistic sloppiness, merely verbal disputes are a natural part of everyday communication. And as they are usually dissolved rather quickly, they typically do not present too much of a problem for

\footnotetext{
2 Note that "(dis)agreement" is used to refer to states and not activities; cf. Cappelen and Hawthorne (2009, p. 60f) and MacFarlane (2014, p. 119) for this distinction. As is common in the debate about merely verbal disputes, the term is to be understood such that two speakers, roughly, disagree on a subject matter $s$ when they have conflicting mental attitudes about $s$. The subject matter of a dispute is thereby to be construed as being heavily dependent on the disputants' fine-grained interests and intentions (cf. Jenkins 2014, pp. 24-5.). Disputes, in contrast, are roughly characterised in behavioural terms in this paper; cf. e.g. Jenkins (2014, p. 13) or Vermeulen (2018, p. 333). (For the sake of brevity, though, I occasionally call disputes that are not merely verbal 'real disputes'.)

${ }^{3}$ Having a merely verbal dispute is just one way for two or more disputants to talk past each other (cf. e.g. Jenkins (2014, p. 22) on mishearings). The distinction between merely verbal disputes and other disputes in which speakers are merely talking past each other can be set aside for the purposes of this paper, though. For further notions of verbalness see 5.2.

${ }^{4}$ Let us call an (atomic or complex) expression $e$ a key expression of a merely verbal dispute between $A$ and $B$ if $e$ grounds $A$ 's and $B$ 's linguistic misunderstanding by being used with different speaker's meaning. Hence, whether an expression is a key expression of a dispute crucially depends on the role the expression plays in an explanation of how the dispute came about despite $A$ 's and $B$ 's non-disagreement on what is discussed. Note that key expressions of merely verbal disputes do not always have to be explicitly uttered by the disputants during their dispute. See also Jenkins (2014, pp. 16-7) on this.

5 This is also meant to cover cases in which two disputants, unaware of the term's indeterminacy, are in fact intending to use this term with its regular meaning. In line with other accounts of merely verbal disputes, this paper takes speakers in such cases as using $e$ differently. (For an alternative take on that, see e.g. Sidelle (2007, p. 91).) On Balcerak Jackson's account, for instance, the speakers would still debate subtly different topics even if they both intended to use the indeterminate term with its regular meaning.

The fact that an indeterminate meaning can be specified in different ways, however, may not be transparent to the disputants. Recognising a term's indeterminacy can be an important theoretical insight, which can dissolve an existing debate. Also note that separating cases in which speakers are using $e$ differently from cases in which speakers are merely having slightly different beliefs about the matter under discussion is notoriously difficult—even more so in cases of linguistic indeterminacy.
} 
us. In philosophy things are much more delicate, though. Philosophers are known for articulating their thoughts rather carefully. An allegation of mere verbalness against a philosophical debate thus not only seems severe, but it also comes with a heavy burden of proof. After all, such allegations accuse diligently executed debates of an unexpected pointlessness. And they are often voiced in an overall deflationist spirit regarding the topics under discussion (cf. Hirsch, 2011; Sidelle, 2007; Sider, 2011).

As Brendan Balcerak Jackson (2014) has pointed out, connecting mere verbalness to deflationism seems too hasty, however. For, according to him, there are disputes that can be described as "merely verbal" which deal with questions that may be characterised as "substantive" in a relevant sense. The first part of this paper supports Balcerak Jackson's general line of argument but refines it in two important ways. To this end, Sect. 2 develops a clear and workable metasemantic notion of substantivity, which goes beyond an appeal to intuitions. Secondly, Sect. 3 comes up with a straightforward explanation of why the developed notion of substantivity is logically, albeit not evidentially, independent of the conception of mere verbalness presented above.

The second part of the paper then tackles this kind of independence thesis from two different sides. First, Sect. 4 explains that even if the disputants' communicative intents are taken into account, merely verbal disputes come out as independent of substantivity as presented thus far. The fifth section then takes a step back from the notions employed in part 1. It points to further salient conceptions of verbalness in the literature. And it lays out a way to engineer various novel notions of substantivity, which can in fact be closely intertwined with some narrower views on verbalness. Section 6 concludes.

Ultimately, the paper aims at further exploring the conceptual landscape. It reorganises notional disarrays and argues for a more careful choice of terminology when it comes to assessing a debate as "merely verbal" or "nonsubstantive". Getting clear about different conceptions of verbalness and the many possibilities to legitimately spell out "substantivity" not only helps in raising more nuanced allegations against philosophical debates; it also discloses how to properly address such allegations.

\section{Substantivity}

Accounts of merely verbal disputes try to capture our fairly robust intuitions about how people can talk past each other. Our intuitions about something "being (non) substantive" seem less stable. "Substantivity" seems more like a term of art. Still, many philosophers appear to share at least some basic intuitions about the notion: having a ring of arbitrariness to them, nonsubstantive questions somehow seem trivial, not worth our time and effort. As we shall see, Ted Sider's (2011) account of substantivity nicely captures such basic intuitions philosophers might have about the notion. Sider developed an account of substantivity, which laid the groundwork for a helpful and better understanding of this term. His account is, to my knowledge, the 
only account of substantivity worked out in detail so far. ${ }^{6}$ Yet, the relation between mere verbalness and substantivity in Sider's sense has so far not been investigated in a systematic manner. ${ }^{7}$ Sider's work therefore provides a natural starting point for us. In addition, the general idea on which Sider's account is based also proves resourceful for the development of various further notions of substantivity, as we will see in the second part of this paper. This section therefore starts by taking a closer look at Sider's conception.

\subsection{Sider's Account}

According to Sider, the property of substantivity applies to linguistic expressions such as yes-no questions and sentences. ${ }^{8}$ Let us focus on questions first. For Sider (2011, p. 49) a yes-no question is nonsubstantive iff it contains an expression $e$ "whose [semantic] candidates are such that (1) each opposing view about the question comes out true on some [semantic] candidate; and (2) no [semantic] candidate carves at the joints [...] better than the rest."

Take the question "Is the pope a bachelor?" as an example. This question is nonsubstantive according to Sider because it contains the expression "bachelor" which has equally joint-carving semantic candidates (=candidate meanings), and its answer depends, roughly speaking, on which of these candidates of "bachelor" is adopted. On at least one of its candidates, the correct answer to the question is a no, but on at least one other candidate, the question is to be answered in the affirmative. Therefore, "Is the pope a bachelor?" lacks substantivity according to Sider.

Here are some more details on Sider's account: take the three possible meanings [unmarried adult male] $\left(m_{1}\right)$, [unmarried adult male eligible for marriage] $\left(m_{2}\right)$, and [fool] $\left(m_{3}\right)$ as an example. Firstly, $m_{1}$ and $m_{2}$ are both candidates, i.e. candidate meanings, of "bachelor", but $m_{3}$ is not. This is because $m_{1}$ and $m_{2}$ at least roughly

\footnotetext{
${ }^{6}$ But cf. Thomasson (2015) who now and then uses "substantive" in opposition to "trivial", whereas for her, trivial questions are questions which can be resolved easily, by conceptual and empirical means. See also Sidelle (2007) for an understanding of substantivity akin to Sider's, or Balcerak Jackson (2014) for an understanding of "nonsubstantive" as "indisputable". (He discusses the relation between indisputable sentences and merely verbal disputes in his (2013), focusing on Hirsch's (2011) account of mere verbalness.) Sometimes philosophers also use "(merely) verbal" and "nonsubstantive" synonymously.

${ }^{7}$ One might suspect right at the outset, like e.g. Vermeulen (2018) does, that Sider's theory of substantivity is simply intended as another view on mere verbalness and speakers talking past each other. Note, however, that Sider explicitly refuses to call a "dispute over whether geese live by 'the bank', in which one disputant means river bank and the other means financial bank" (2011, p. 47) nonsubstantive. Hence, Sider's account of substantivity does not focus on the very same phenomenon of talking past each other that philosophers like Jenkins, Vermeulen or Balcerak Jackson are after.

${ }^{8}$ Occasionally, when being concerned with situations in which the parties utter sentences that lack substantivity, Sider also applies the term "nonsubstantive" to disputes. Also note that there is a way of speaking according to which any dispute involving genuine disagreement about the topic under discussion already qualifies as being substantive. On this narrower notion of substantivity, substantivity and non-verbalness come out as two sides of the same coin (see also the beginning of Sect. 3 on this). While acknowledging this manner of speaking, the paper focuses on a richer notion of substantivity, which is (for the sake of clarity) used for questions and sentences only. We will come back to various further notions of substantivity and verbalness in Sect. 5 .
} 
fit the usage of "bachelor" in our linguistic community (or would fit it in a possible community relevantly similar to ours), but [fool] clearly does not. We could (have) use(d) "bachelor" with the possible meanings $m_{1}$ and $m_{2}$ "without seeming "semantically alien"" (Sider, 2011, p. 50), but the same is not true of $m_{3}$. So, $m_{1}$ and $m_{2}$ are both candidates of "bachelor" but $m_{3}$ is not. Consequently, it just does not matter how "Is the pope a bachelor?" would have to be answered if "bachelor" meant [fool], because [fool] does not even match our usage of "bachelor".

It does matter, however, how the question is to be answered under $m_{l}$ or $m_{2}$ as possible meanings of "bachelor". For $m_{1}$ and $m_{2}$ not only fit our usage of "bachelor" but also seem to be equally natural or joint-carving. ${ }^{9}$ According to Sider, neither option carves the objective joints of nature better than the other, since "bachelor" refers to different but equally natural subsets of male adults under each meaning. It is therefore relevant whether conflicting answers to the question turn out to be correct under $m_{1}$ and $m_{2}$. The answer to "Is the pope a bachelor?" is a yes under $m_{l}$, since the pope is an unmarried adult male. However, "Is the pope a bachelor?" is to be answered in the negative under $m_{2}$; i.e. the answer to the question is a no under [unmarried adult male eligible for marriage]. This is because the pope is ex officio not eligible for marriage. The question "Is the pope a bachelor?" is therefore nonsubstantive on Sider's account.

Note that this result seems to accord with a vague feeling one may have about this question. The question can strike us as being trivial, "just about words" and not relating to any "fact of the matter" so that "nothing turns on the verdict" which answer (if any) to it is right. Answering it does not seem worthy of our time and effort. And, intuitively, this seems different for a question such as "Was Kant a bachelor?" which counts as substantive on Sider's account. For "Was Kant a bachelor?" is to be answered affirmatively under each candidate meaning of "bachelor".

Altering Sider's terminology a bit, let us say that two or more possible meanings $m_{1}, m_{2} \ldots m_{n}$ are equally good meaning options for an expression $e$ iff $m_{1}, m_{2} \ldots m_{n}$

i. roughly match our usage of $e$, and

ii. are equally joint-carving, and no meaning (which also fulfils i.) is more joint-carving.

On Sider's account, a given question $q$ containing an expression $e$ lacks substantivity only if there are two meaning options for $e$ which meet both criteria and under which $q$ is to be answered differently.

When engineering this notion of substantivity Sider has his metasemantic theory of reference magnetism in mind-a theory which is designed to explain how words get their meanings (cf. Sider, 2011, ch. 3.2). According to this view, the non-linguistic world has an objective metaphysical structure partly determining the meaning of our terms. It is important to be clear, though, that for Sider, metasemantics is what is important for substantivity, not semantics. According to him, "sentences that

\footnotetext{
9 Sider's account is based on David Lewis' notion of naturalness (cf. e.g. Lewis 1983).
} 
express the same proposition can differ in substantivity" (2011, p. 51) because they can contain synonymous expressions that have different meaning candidates. What is more, according to Sider, (lack of) substantivity is not to be equated with semantic (in)determinacy either. On his account, a question $q$ can be substantive despite its meaning being indeterminate. And it can be nonsubstantive even if its meaning is clearly determinate. So, it is important to note that two meaning options $m_{1}$ and $m_{2}$ can be equally good metasemantic options for a term $e$ in Sider's sense even if $m_{l}$ is $e$ 's actual meaning but $m_{2}$ isn't. In such a case, the term's actual meaning does not "stand out from the metasemantic background/surroundings", as Sider likes to put it (cf. e.g. 2011, p. 59 or p. 65). If question $q$ is nonsubstantive, the meaning of $e$ in $q$ could just as easily have been different. At this point, Sider's controversial view on metasemantics comes into play: reference magnetism defines conditions for $e$ having equally good semantic alternatives in Sider's sense. If there are possible meanings which a) roughly match our usage of $e$ and b) are as joint-carving as $e$, then the meaning of $e$ could easily have been one of these meanings-meanings that are, metasemantically speaking, not relevantly different from the determinate meaning $e$ may actually have. Hence, the question lacks substantivity in Sider's sense (provided that it is to be answered differently depending on which of $e$ 's equally good meaning options is adopted).

The assumption of a deep objective structure of the non-linguistic world bears a heavy metaphysical load though. ${ }^{10}$ Moreover, it is in general highly debated which metasemantic theory is the best choice. ${ }^{11}$ Even if "substantivity" is largely a term of art, tying it to one specific theory (or set of theories) unnecessarily narrows the term's applicability. It would certainly be preferable to have a less controversial and broader notion of substantivity which different parties in philosophy could agree to.

\subsection{A Generalised Notion of Metasemantic Substantivity}

Fortunately, one does not have to look far to find a less controversial and broader metasemantic notion of substantivity which preserves Sider's core idea. The first step to a more generalised account of substantivity is just to refrain from referring to specific metasemantic criteria. Instead of referring to e.g. reference magnetism, a more generalised account can leave it open which criteria really specify equally fitting meaning alternatives. The crucial step is to apply a broader notion of a good meaning option freed of Sider's account and its specific criteria. ${ }^{12}$

A possible meaning $m$ should be understood as a good meaning option for an expression $e$ in a linguistic community $l$ iff $m$ meets the relevant criteria for being

\footnotetext{
10 Sider briefly discusses scepticism about structure in his (2011, ch. 1.2).

11 There are many prominent alternatives to reference magnetism, e.g. Kripke's causal theory (cf. Kripke 1980), Davidson's truth-maximising account (cf. e.g. Davidson 1974) or mentalistic theories of meaning like e.g. Grice's (cf. Grice 1957, 1969), prominently criticised by Burge (1979). For a helpful overview of different foundational theories of meaning see e.g. Speaks (2018).

12 One can take further steps to generalise this idea of substantivity beyond a metasemantic notion. This will become clear in Sect. 5 .
} 
the meaning of $e$ in $l$. Which meaning criteria are correct, however, need not be spelled out for a more generalised understanding of substantivity:

Nonsubstantive $_{q}$ A yes-no question $q$ is nonsubstantive in a context $c$ iff

i. $\quad q$ contains an expression $e$ which has at least two different equally good meaning options $m_{1}$ and $m_{2}$, and

ii. $\quad q$ in $c$ is to be answered in the affirmative under $m_{l}$ but to be answered negatively under $m_{2}$.

So "Is the pope a bachelor?" is a nonsubstantive question in context $c$, according to Nonsubstantive $q$ if there are at least two different equally good meaning options for "bachelor" (i.) and if the question in $c$ is to be answered with a yes under at least one of these options but with a no under at least one other option (ii.). A question is

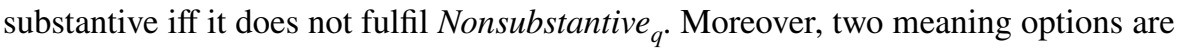
construed as equally good if they are (i) good meaning options, i.e. fulfil the relevant meaning criteria, and if they equally fulfil the relevant criteria.

Note that it is possible according to Nonsubstantive $q$ that there is exactly one meaning option for each expression which fulfils the relevant meaning criteria. Then in fact no question would lack substantivity. Additionally, Nonsubstantive leaves it open whether being a good meaning option can come in degrees at all. Depending on which metasemantic picture is accurate, a meaning might either fulfil the relevant criterion/criteria or not fulfil it/them. So, not only is it heavily dependent on the right metasemantic theory which questions count as nonsubstantive in the sense developed; whether there are any nonsubstantive questions at all will also vary depending on which metasemantic account is correct. Thirdly, a question can also be nonsubstantive in one context but substantive in another (see Sider, 2011, p. 51 for an example). And what is more, Nonsubstantive $q$ does not in principle preclude that two meaning options $m_{1}$ and $m_{2}$ for a term $e$ are equally good even when $m_{1}$ but not $m_{2}$ is the determinate meaning of $e$. Expression $e$ could just as easily have meant $m_{2}$ and is not relevantly different from $m_{1}$ given the correct metasemantic criteria. The two options are then "equally good" in Sider's sense of this term. (But see also Sect. 5.1 for a variety of ways to spell out "equally good".)

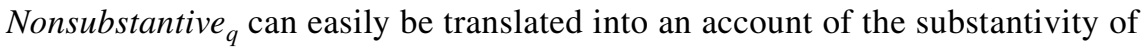
sentences (cf. Sider, 2017, p. 2470):

Nonsubstantive A sentence $s$ is nonsubstantive in a context $c$ iff

i. $\quad s$ contains an expression $e$ which has at least two different equally good meaning options $m_{1}$ and $m_{2}$, and

ii. $\quad s$ in $c$ expresses a truth under $m_{1}$ but a falsehood under $m_{2}$.

This definition classifies "The pope is a bachelor" as a nonsubstantive sentence provided that "bachelor" has different equally good meaning options (i.) and the sentence expresses a truth under one of these options and a falsehood under

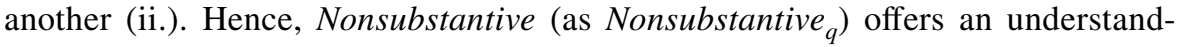
ing of substantivity which preserves the core idea of Sider's account but frees it 
from its most controversial background assumptions. In Sect. 5, I will come back to this generalised metasemantic idea of substantivity and carve out a number of further notions akin to Nonsubstantive. But let's first take a closer look at the relation between mere verbalness and substantivity as construed in this section.

\section{Substantivity and Merely Verbal Disputes}

Sometimes philosophers simply vary their thoughts when speaking of "(merely) verbal" and "nonsubstantive" disputes interchangeably. Yet, philosophers also construe verbalness and deflationism as two sides of the same coin (for more on that see Sect. 5). The present section briefly revisits Balcerak Jackson's discussion of the relation between mere verbalness and (metasemantic) substantivity as detailed above. I then offer a straightforward but so far overlooked explanation of the logical (albeit not evidential) independence of these two phenomena (Sect. 3.2). In addition, this section paves the way for the second part of the paper, in which the independence thesis advanced in this section will be subjected to closer scrutiny.

\subsection{Logical Independence}

The generalised metasemantic picture of substantivity as detailed above construes substantivity as a property of linguistic expressions such as yes-no questions and sentences. But as Balcerak Jackson (2014) has pointed out, merely verbal disputes should not simply be understood as disputes about nonsubstantive questions. This has already become evident in the introduction. After all, Anna intends to answer the question of whether one million is $10^{6}$ and Ben's statement is meant to provide an answer to the question of whether one billion is $10^{6}$. These questions are apparently substantive on the account given. Neither of them contains any expression for which there are different yet equally good meaning options, i.e. meaning options equally fulfilling the relevant metasemantic criteria. On the contrary, given that both questions merely contain number terms and logical operators, the meaning of all terms seems to be "as specific as we could hope for" (Balcerak Jackson, 2014, p. 50). Apparently, then, a merely verbal dispute should not simply be understood as a dispute about one or more nonsubstantive question(s).

In addition, it is also possible that two (or more) parties are having a merely verbal dispute when the sentences they utter lack substantivity. (See also the next subsection on this.) For the sake of the argument let us follow Sider here and assume that the sentence "The pope is a bachelor" is in fact nonsubstantive. Clearly, the following dispute between Ada and Bertie can then be merely verbal in the sense presented:

Ada: "The pope is a bachelor." (SI)

Bertie: "The pope is not a bachelor." (S2) 
Just imagine a context $c 1$ in which Ada and Bertie agree on all relevant facts concerning the pope: both know that the pope is an unmarried adult male who is ex officio not eligible for marriage. The two are just using "bachelor" differently. Ada uses "bachelor" according to $m_{l}$ : by uttering $S 1$ in $c l$ she just wants to convey the correct thought that the pope is an unmarried adult male (because she, say, takes Bertie, who has an aversion to religion, to in fact not know this). Bertie, however, erroneously thinks that what Ada wants to convey with her utterance is the false belief that the pope is an unmarried adult male eligible for marriage. He replies to Ada's utterance by using "bachelor" in $S 2$ according to $m_{2}$. Obviously, then, in context $c 1$ Ada and Bertie are having a merely verbal dispute (they are simply speaking about subtly different topics) but their utterances $S 1$ and $S 2$ are nonsubstantive.

It is easy to see that disputants can also have a real dispute and yet utter nonsubstantive sentences in the sense detailed. Take again Ada's and Bertie's dispute consisting of the nonsubstantive sentences $S 1$ and $S 2$. But this time imagine another context (c2) in which both speakers use "bachelor" according to $m_{1}$ but disagree about the pope's marital status. What they both mean by "bachelor" in $c 2$ is [unmarried adult male]. But whereas Ada knows that the pope is unmarried, ignorant Bertie in fact believes that the pope has a wife. As a result, Ada and Bertie are clearly having a real dispute in $c 2$. They use "bachelor" with the same speaker's meaning and have a relevant disagreement (they disagree on the pope's marital status). Yet the sentences uttered by them in order to convey their conflicting thoughts are nonsubstantive.

The upshot of these considerations seems clear: if we follow prominent accounts of mere verbalness and employ a generalised metasemantic notion of substantivity based on Sider's renowned account, we can find no logical connection between mere verbalness and substantivity. ${ }^{13}$

\subsection{Explanation and Evidence}

The independence of mere verbalness and substantivity as construed so far should not come as a real surprise. After all, the key to a proper understanding of mere verbalness is the notion of speaker's meaning. When it comes to two or more parties having a merely verbal dispute, it is largely irrelevant what they utter and which semantic properties their utterances have. Rather, what is important is what the disputants mean by their utterances. In this sense, merely verbal disputes are all about pragmatics. In contrast, whether a sentence is nonsubstantive in a generalised Siderian sense depends on whether there are equally good meaning options for one or more of its sub-sentential parts. To be sure, which relevant meaning options there are for a term might eventually depend on what speakers usually mean by uttering the term. But what a certain speaker means by uttering a term in a certain context

\footnotetext{
13 This is not supposed to mean that there are no interesting similarities between the two phenomena. (A lack of) substantivity, for instance, is still a verbal matter in the sense of concerning words and meaning candidates.
} 
can deviate from what speakers usually mean by this term. In light of this it should be no surprise that the two phenomena presented are logically independent.

Despite their overall independence it is important to note though that mere verbalness and metasemantic nonsubstantivity are evidentially connected. If a key expression has different yet equally good meaning options, there is a sense in which disputants can make different yet equally good use of this term. Given that disputants generally use terms with meanings that fulfil the relevant meaning criteria, the existence of several good meaning options for a certain expression thus at least somewhat increases the likelihood that this expression is in fact used differently. It just provides an easy and charitable explanation of the disputants' divergent usages. (If, for instance, a key expression of a dispute is semantically indeterminate, it seems somewhat more likely that the disputants are actually using this expression differently. The disputants then have different yet equally good options of how to use the term.) Hence, looking out for nonsubstantive statements in a debate might contribute to discovering merely verbal disputes in this debate. And figuring out the equally good meaning options of a term might often amount to figuring out the difference in usage of the term which grounds the merely verbal dispute.

Conversely, for analogous reasons, an evidential relation also seems to hold in the opposite direction. That two disputants are having a merely verbal dispute can be taken as weak evidence for a lack of substantivity of their utterances as detailed so far. If two disputants are having a merely verbal dispute, they use a key expression of their dispute differently. Yet, if competent speakers are using an expression differently, this is prima facie evidence that there are actually two different yet equally good options of how to use the term. Of course, there are many merely verbal disputes in which speakers just use terms in a "semantically alien" way, as Sider (2011) would put it (cf. Anna's use of "billion"). However, also note that improper uses are particularly less likely to occur in long-standing philosophical debates. If we have reasons to assume that two camps of a philosophical debate are just using a relevant term slightly differently, then this seems to provide some evidence that the meanings employed by these camps are equally good in the sense explained. ${ }^{14}$

\section{Spurious Substantivity and SMubstantivity}

So far, the independence thesis presented in the last section seems quite solid. Yet this section will lay out a problem for the generalised metasemantic notion of substantivity, which also raises concerns about the proclaimed independence of verbalness and nonsubstantivity.

"Substantivity" as introduced above is a notion that applies to linguistic expressions only. It could seem desirable, though, to extend this notion to accommodate

\footnotetext{
14 See also Balcerak Jackson (2014, p. 48) on how the indisputability of a sentence provides evidence for the mere verbalness of a dispute, and Chalmers (2011) for a general heuristic for how to detect merely verbal disputes.
} 
disputants' communicative intents and interests as well. To see why, consider the following two cases:

Ada: "The pope is a bachelor." (S1)

Bertie: "The pope is not a bachelor." $(S 2)$

Assume that by uttering $S 1$ Ada just wants to point out that the pope is unmarriedand nothing else. And by uttering $S 2$ ignorant Bertie intends to convey simply the opposite: He just means that the pope is not unmarried. So, in this context, each speaker apparently has one rather specific thought in mind, which (s)he wants to communicate to the other party. Both intend to state something determinate about the pope's marital status, but not his alleged bachelorhood. Yet, as it seems, Nonsubstantive just categorises $S 1$ and $S 2$ as nonsubstantive.

Surely, "substantivity" is largely a term of art. (And Sect. 5 will in fact present a way to engineer an abundance of novel notions which could, in principle, be paired with this term.) But still, it seems reasonable to develop our basic understanding of substantivity in a sufficiently broad framework-one which can offer a way to interpret both speakers as intending to state something substantive in the context given. One might aim for such an understanding as it actually seems "natural" (Sider, 2011, p. 52) to some philosophers to categorise such cases as cases in which something substantive is at issue. Yet so far it seems unclear how Nonsubstantive can provide such an interpretation of cases like the above.

Compare this first case to the following second case. Assume that Ernie and Fred are standing on St. Peter's Square in Rome, both talking about the fact that most Englishmen under the age of 25 are bachelors. Suddenly the pope appears on the famous balcony in front of them. Ernie points his finger at him, and says:

Ernie: "This guy is what most Englishmen under the age of 25 are." (S3)

And Fred replies:

Fred: "No, he is not what most Englishmen under the age of 25 are." (S4)

Nonsubstantive classifies $S 3$ and $S 4$ as substantive in this context of use. For the expression "what most Englishmen under the age of 25 are" might refer to the property of bachelorhood in the given context, but that does not make e.g. [unmarried adult male] a good option for this expression's general linguistic meaning. (Or so critics of Nonsubstantive might say; let us grant them the point.) The result given by Nonsubstantive, however, might again seem unsatisfying. After all, by uttering S3 and $S 4$ Ernie and Fred just intend to talk about the pope's bachelorhood. It seems preferable to have an account of metasemantic substantivity which also considers Ernie's and Fred's communicative intents and explains in what sense something nonsubstantive might be at issue in their case.

This section presents a way in which the metasemantic account of substantivity outlined above can be enriched to meet the challenges of such cases. It introduces a new notion of a speaker meaning something (non)substantive, which heavily depends on Nonsubstantive (Sect. 4.1). The section then explores whether this new 
notion raises problems for the advocated independence of nonsubstantivity and mere verbalness (Sect. 4.2).

\subsection{Spurious Substantivity}

To get the general idea of how the account of substantivity presented so far can provide a satisfying interpretation of cases like the above, consider the following situation. Assume there are two philosophers, George and Hannah, enjoying their holiday in Rome. Hannah asks George: "Is the pope a bachelor?" The only thing that Hannah intends to find out by asking her question is whether the pope is unmarried. George has good reason to suspect this. Pompous as he is, though, he replies the following way: "I don't know, Hannah. Is he? How your question is to be answered seems to depend on how you understand 'bachelor' here. Following Sider, your question is nonsubstantive. But I guess what you actually want to know is whether the pope is unmarried, right? That I can answer! He is indeed. (Next time please be more careful when phrasing your question.)" Annoying as such an answer might be, pompous George seems right: the question Hannah actually asked is nonsubstantive in the sense detailed. Still, we might have the feeling that something substantive is at issue here, and the reason for this is simple: had Hannah been more careful and had she uttered what she means, i.e. what she intends to find out by asking the nonsubstantive question, Hannah would have uttered a substantive question. So, given Hannah's communicative intent, her nonsubstantive question "Is the pope a bachelor?" is substitutable with the substantive question "Is the pope unmarried?" And that is why her actual (nonsubstantive) question has a ring of substantiveness to it—or so I would argue.

Coming back to the sample cases from above, here are some more details about this idea of defending Nonsubstantive against the alleged counterexamples. The distinction between (i) the sentences the disputants utter (S1-S4) and (ii) those thoughts or statements they really intend to communicate is crucial. Consider Ada's sentence $S 1$ again and call the context of utterance described first above $c 3$. According to Nonsubstantive, Ada's utterance

Ada: "The pope is a bachelor." $(S 1)$

lacks metasemantic substantivity in $c 3$. Yet taking into account Ada's communicative intent in uttering $S 1$ in $c 3$, her nonsubstantive utterance $S 1$ seems $s u b$ stitutable in $c 3$ with "The pope is unmarried" $(S 1+)$. The only thing Ada wants to communicate by uttering $S 1$ in this context is the content of $S 1+$, i.e. that the pope is unmarried. Ada just expresses this thought, infelicitously, by uttering the nonsubstantive $S 1$. Had she properly uttered what she means-i.e. had she uttered $S 1+$, a sentence having the same semantic value as the sentence Anna intended to communicate by $S 1$ in $c 3$-then Anna would have uttered a substantive sentence. In this sense $S 1+$ is substitutable with $S 1$ in $c 3$, and $S 1$ can be called spuriously substantive in $\mathrm{c} 3$ :

Spurious A sentence $S$ uttered by a speaker $A$ is spuriously substantive/nonsubstantive in a context $c$ iff 
i. $\quad S$ is nonsubstantive/substantive in $c$, but

ii. there is another sentence $S+$ which is substantive/nonsubstantive in $c$ and $S+$ is substitutable with $S$ in $c$, given $A$ 's communicative intent in uttering $S$ in $c$.

According to Spurious, $S 1$ is spuriously substantive in $c 3$ because $S 1$ is nonsubstantive in $c 3$ but there is also a sentence substitutable with $S 1$ which is substantive.

This provides a straightforward explanation for why philosophers might find it natural to say that something substantive is at issue in $c 3$ : because there is a substantive sentence $S 1+$ which Ada would have uttered, had she properly uttered what she intends to communicate in $c 3$. (The same strategy can be applied to Bertie's utterance; $S 2$ is spuriously substantive in $c 3$ as well.)

An analogous response also delivers a satisfying interpretation of the second case, in which Ernie and Fred utter substantive sentences, S3 and S4. In this case, there are two nonsubstantive sentences, $S 3+$ and $S 4+$, in the background-sentences which are substitutable with $S 3$ and $S 4$, taking into account how Fred's and Ernie's communicative intents would have been properly expressed: "The pope is a bachelor" $(S 3+)$ and "No, he is not a bachelor" $(S 4+) . S 3$ and $S 4$ are therefore spuriously nonsubstantive. And this provides an explanation for why philosophers might find it natural to classify Ernie's and Fred's dispute as one in which something nonsubstantive is at issue. ${ }^{15}$

Nonsubstantive hence provides resources for satisfying interpretations of cases like the above. Moreover, it also grounds a natural understanding of phrases like "By uttering sentence $S$ speaker $A$ means something substantive/nonsubstantive in context $c$ ". This understanding is captured in S(peaker's)M(eaning)(S)ubstantivity:

SMubstantivity By uttering a sentence $S$ speaker $A$ intends to convey something substantive/nonsubstantive in a context $c$ iff

i. there is another sentence $S+$ which is substantive/nonsubstantive in $c$, according to Nonsubstantive, and

ii. $S+$ is substitutable with $S$ in $c$, given $A$ 's communicative intent when uttering $S$ in $c$.

\subsection{Merely Verbal Disputes and SMubstantivity}

The notion of spurious substantivity and the notion of somebody meaning something (non)substantive further enrich the account of metasemantic substantivity laid

\footnotetext{
15 Sider (2011, p. 52) very briefly touches upon a case similar to the first case discussed above and also alludes to a solution that is similar to the one sketched here: "We might account for this by distinguishing the question the [...] [disputants; V.K.] really ask [...] from the question they really care about [...] and applying the official account, as-is, to these questions." A problem case of the second kind is not discussed by Sider.
} 
out so far. They are, however, easily seen as bringing up two new and potentially problematic questions about the relation between merely verbal disputes and (non) substantivity:

(1) Is it possible that a dispute between two disputants is merely verbal if both mean something substantive by uttering conflicting sentences (" $p$ "; " $\sim p$ ")?

(2) Is it possible that two disputants are having a real dispute if both mean something nonsubstantive by uttering conflicting sentences (" $p$ "; “ $\sim p$ ")?

Let us take question (1) first. To answer it, consider Ada's and Bertie's dispute again:

Ada: "The pope is a bachelor." (S1)

Bertie: "The pope is not a bachelor." $(S 2)$

Is it possible that both mean something substantive in the sense of SMubstantivity but are having a merely verbal dispute nevertheless? It is indeed. Take a context $c 4$ in which Ada and Bertie agree on all the relevant non-linguistic facts concerning the pope: in $c 4$ both know that the pope is an unmarried adult male who is ex officio forbidden to marry. Both, however, mean something different by the expression "the pope is a bachelor". And that is why they are talking past each other.

Let us look at Bertie first: by uttering the nonsubstantive $S 2$ Bertie intends to convey the (true) thought that the pope is not an unmarried adult male eligible for marriage. And because the sentence "The pope is not an unmarried adult male eligible for marriage" is substantive, Bertie means something substantive by uttering $S 2$, according to SMubstantivity. Given Bertie's communicative intent in $c 4$, the substantive sentence "The pope is not an unmarried adult male eligible for marriage" is substitutable with the nonsubstantive $S 2$ in $c 4$.

Now turn to Ada: assume that by uttering "The pope is a bachelor" (S1) Ada just wants to convey the true thought that the pope is unmarried. Because the sentence "The pope is unmarried" properly expresses what Ada wants to communicate and is also substantive, Ada means something substantive with her utterance, too.

So, despite them both meaning something substantive by their utterances in $c 4$, the two speakers are clearly having a merely verbal dispute. Both agree on the relevant facts, yet use "bachelor" with different speaker's meaning. By uttering S1 Ada just wants to tell Bertie that the pope is unmarried. Bertie, however, erroneously taking Ada to mean that the pope is an unmarried adult male eligible for marriage, responds by uttering $S 2$.

To see that question (2) is to be answered affirmatively, too, look at Ernie's and Fred's dispute again:

Ernie: "This guy is what most Englishmen under the age of 25 are." (S3)

Fred: "No, he is not what most Englishmen under the age of 25 are." (S4)

Take a context $c 5$ in which it is again evident that both disputants are talking about the fact that most Englishmen under the age of 25 are bachelors. Furthermore, by "this guy" and "he" the speakers are referring to the pope. In $c 5$, however, Fred 
thinks that the pope is married and therefore not a bachelor whereas Ernie knows that the pope is unmarried. So, there is genuine disagreement between them: they disagree on whether the pope is a bachelor, since they disagree on whether the pope is unmarried. Their dispute therefore cannot be merely verbal.

But despite their having a real dispute, by uttering $S 3$ and $S 4$ Ernie and Fred intend to convey something nonsubstantive in the sense detailed. Because what Ernie means by uttering $S 3$ is, of course, that the pope is a bachelor, and what Fred means by uttering $S 4$ is just the opposite, namely that the pope is not a bachelor. Thus, although Ernie and Fred are having a real dispute, they both mean something nonsubstantive by their utterances, according to SMubstantivity. The nonsubstantive "The pope is a bachelor" and "The pope is not a bachelor" are substitutable with S3 and $S 4$ respectively, given Ernie's and Fred's communicative intents in $c 5$. So, not only (1) but also question (2) is to be answered in the affirmative.

As a result, the independence thesis still stands. Even if a new notion based on the above understanding of Nonsubstantive is taken into account-a notion which takes the disputants' communicative intents seriously-merely verbal disputes and metasemantic substantivity come out as two independent phenomena.

Let us now take a step back. At this point, it seems important to note that we have so far only worked with a particular conception of verbalness. Following prominent accounts like those of Balcerak Jackson, Jenkins or Vermeulen, we have focused on disputes in which speakers (i) are not in any relevant disagreement but are (ii) merely using a key expression of their dispute with different speaker's meaning; the disputants are therefore simply talking past each other. Moreover, our focus has been on a generalised metasemantic picture of substantivity based on Sider's renowned account. This approach has certainly led to a more thorough understanding of the independence of mere verbalness and nonsubstantivity so construed. Yet the foregoing approach also opens up a number of further questions.

In addition to the notion of mere verbalness, can we identify other interesting notions of verbalness that are salient in philosophical research? A related question would also be whether there are alternative notions of substantivity. How are these further notions related to the generalised Siderian idea of substantivity outlined above (if related at all)? And, most importantly: if other notions of verbalness and substantivity do come into play, how does this affect the independence thesis laid out in Sect. 3 and defended in the present section? In what follows, I will address these questions, starting with the phenomenon of substantivity.

\section{Varieties of Substantivity, Notions of Verbalness, and the Independence Thesis Revisited}

\subsection{Varieties of Substantivity}

So far, we have focused on a generalised metasemantic notion of substantivity, developed along the lines of Sider's prominent account. Roughly, a sentence $s$ is nonsubstantive, we have said, iff two conditions are met: (i) $s$ contains an expression 
$e$ which has at least two different equally good meaning options (i.e. there are possible meanings $e$ could easily have had which equally fulfil the relevant metasemantic criteria), and (ii) $s$ expresses a truth under one of these meaning options but a falsehood under another.

It is interesting to note that this idea of substantivity could be generalised even further. A sentence could not only lack (or not lack) metasemantic substantivity. Given a certain function of $e$ in our linguistic community, meaning alternatives could also be legitimately compared and evaluated along various other dimensions. This gives rise to a variety of further notions of substantivity philosophers could work with. Let me give an example.

Assume that the function of the term "content" is to pick out, roughly, what speakers are saying with their assertions. ${ }^{16}$ At least at first glance, this role can be played by different notions of content, however. For the sake of simplicity, let's only focus on two: (i) the Fregean notion of thought (c), and (ii) some notion of content $\left(c^{*}\right)$ according to which the content of sentences like

(S5) I am 32 years old

does not vary with a change in who is speaking. Now, some might think that $c$ and $c^{*}$ aren't equally good meaning options of "content" in the metasemantic sense detailed above. They just see one option as failing to meet the relevant meaning criteria ( $c$ and $c^{*}$ might not equally match usage, for instance). However, even if we subscribed to this, we could still take $c$ and $c^{*}$ as equally good notions of content along some other dimension of evaluation. Even if $c$ and $c^{*}$ aren't equally good notions metasemantically speaking, the two meaning options might, for instance, still be equally fitted to figure in philosophical research; they might be equally useful for our theoretical purposes - and in this sense: equally good.

Just for the sake of the argument, let's in fact take $c$ and $c^{*}$ as not equally fulfilling the relevant metasemantic criteria. As a result, we consider $S 6$ to be metasemantically substantive:

(S6) S5 uttered by Eve has a different content than $S 5$ uttered by Greg.

Even in this situation, I think, we can easily come up with a slightly different but related notion of substantivity according to which $S 6$ is nonsubstantive. To see this, simply assume that $c$ and $c^{*}$-while not being equally good metasemantically speaking - are on a par in some further relevant respect. For instance, take them to be equally useful notions for philosophical research. That is, take $c$ and $c^{*}$ to be equally good meaning options in a further sense of "equally good". S6 would then come out as nonsubstantive on a further interesting and seemingly legitimate reading of this term. For, depending on which option $-c$ or $c^{*}$-is adopted, $S 6$ would either come out true or false.

The upshot is that the large number of available readings of "equally good" can be seen as constituting a large number of subtly different notions of substantivity.

$\overline{16}$ For more on linguistic functions see e.g. Prinzing (2018) or Thomasson (2020). 
Although $S 6$ might be metasemantically substantive on the account presented in Sect. 2, the sentence could still come out as nonsubstantive on some further reading of "equally good"-e.g. a reading of this term that only takes theoretical virtue as the standard of evaluation. (For more examples see below.) This opens up a wide conceptual spectrum. Thus, when raising allegations of "nonsubstantiveness", it is crucial to be clear which sense of "equally good", which standard of evaluationand consequently: which notion of substantivity-is employed.

As there are infinitely many meaning options for a term, and as "equally good" can also be detailed in a huge number of ways, I suggest to classify questions or sentences as being (non)substantive (i) relative to particular standards of evaluation and (ii) relative to a particular set of 'good' meaning options (e.g. $c$ and $c^{*}$ ). Not all standards of evaluation - and thus not all notions of substantivity-are equally interesting or relevant for philosophical research, of course. The generalised Siderian notion of metasemantic substantivity might still be most fruitfully employed in many contexts. Still, given the flexibility in spelling out "equally good", there are large numbers of various, subtly different notions of (non)substantivity. I happily embrace this result. For, as we will see in the following, many notions can be fruitfully employed in philosophy. And acknowledging the existing variety of different notions eventually leads to a more nuanced picture of the independence thesis. Also note that, even on the account given, all notions are tied together by a common idea: whenever there is some lack of substantivity, we find equally good meaning options (in some relevant sense) calling for conflicting evaluations of sentences (or conflicting answers to questions).

\subsection{Two Notions of Verbalness}

As laid out in 5.1, there is a rather basic idea of substantivity that underlies the metasemantic notion detailed in Sects. 2 and 4. According to this idea, a sentence $s$ is nonsubstantive iff two conditions are met: (i) $s$ contains an expression $e$ which has at least two different equally good meaning options on some dimension of evaluation; and (ii) $s$ expresses a truth under one of these meaning options but a falsehood under another. Given the variety of ways to reasonably spell out "equally good", this basic idea of substantivity can be further specified into various relevant notions, only one of them being the generalised metasemantic notion used so far. Keeping this in mind, let us now come back to verbal disputes.

First of all, it is important to notice that there are at least two remarkably different phenomena listed under the heading of "verbal disputes" in the literature. One is the phenomenon of merely verbal disputes, already detailed in the introduction. Disputes, however, can also be verbal in the sense of simply being about words. ${ }^{17}$ Consider the following example of an explicit metalinguistic dispute:

\footnotetext{
17 There are further useful notions of verbalness in the literature like e.g. Chalmers' (2011, pp. 525-6) notion of partly verbal disputes (roughly, disputes in which disputants are using a key expression differently but are still disagreeing on what the other party is communicating with his/her statement). Such disputes are verbal in the sense that speakers are using a linguistic expression differently. They are not merely verbal, though, as the speakers disagree on the truth value of what each of them intends to convey.
} 
Rob: "The term 'sexual harassment' should be applied to intra-marital assaults as well."

Serge: "I disagree."

Assume that things are as they seem and Rob and Serge are disagreeing on the meaning of "sexual harassment" and how to best use this term. They are having a dispute about language: Rob thinks we should use "sexual harassment" for certain transgressions happening inside marriages, too; Serge disagrees. He thinks the term should only be applied to assaults outside relationships.

This way of disputes being verbal should certainly be separated from disputes being merely verbal in the sense of Jenkins, Balcerak Jackson and others: Rob and Serge are having a verbal dispute without having a merely verbal dispute. After all, they are not merely talking past each other but are genuinely disagreeing about how to use a certain term.

Note that metalinguistic disagreements need not be expressed as explicitly as in Rob's and Serge's dispute. Speakers can also have a metalinguistic dispute by using the term(s) under discussion differently instead of mentioning it (them) (cf. Plunkett and Sundell (2013) and Plunkett (2015) on metalinguistic negotiations). To see this, look at the following disagreement:

Romy: "A married man can sexually harass his husband or wife."

Sara: "I disagree. A married man cannot sexually harass his husband or wife."

Assume that, as they would in a merely verbal dispute, Romy and Sara are using "sexually harass" differently, making each of their statements coming out true in their "own language", as Hirsch (2011) would put it. It is important to be clear that this difference in usage is compatible with the speakers having a so-called metalinguistic negotiation. In this case, Romy and Sara would be genuinely disagreeing on roughly the same topic as Rob and Serge: how to best use "sexually harass". (In contrast to merely verbal disputes, metalinguistic disputes also do not dissolve even if the parties are aware of their adversary's different usage of language.)

Many metalinguistic disputes are clearly worth having. Yet in some cases of metalinguistic negotiation, the sentences uttered by the speakers could be categorised as nonsubstantive. Take a metalinguistic negotiation between two speakers $A$ and $B$ concerning the usage of a certain term $e$ :
A: "This is an $E . "$
$B$ : "I disagree. This is not an $E$."

Whereas $A$ intends to communicate with her statement, say, that " $E$ " $(e)$ should be used with meaning $m_{l}$ (such that $A$ 's assertion comes out true), $B$ argues for using $e$ with meaning $m_{2}$ (such that $B$ 's assertion comes out true). The speakers are thus disagreeing on how to best use $e$ and are not having a merely verbal dispute. Nonetheless, their dispute can be pointless and their utterances may still be nonsubstantive in a relevant sense if the meaning options advocated by the speakers are relevantly on a par. 
For a first example, assume that $A$ and $B$ are having a dispute over the correct linguistic meaning of $e$. $A$ advocates $m_{l}$ because she takes $m_{l}$ to be the correct meaning of $e$. Speaker $B$, in contrast, argues for using $e$ with meaning $m_{2}$ since he considers $m_{2}$ to be the correct meaning of $e$. Now, their dispute might be worth having if $m_{2}$ is the only correct meaning of $e$, for instance. In a case of $e$ being e.g. semantically indeterminate between $m_{1}$ and $m_{2}$, however, $A$ 's and $B$ 's dispute would seem pointless. There would just be no semantic fact of the matter which meaning option is the better choice.

Let me give a further example. Suppose $e$ has a determinate meaning- $m_{2}$-and $A$ is perfectly aware of this. Nevertheless, in contrast to speaker $B, A$ advocates using $e$ with meaning $m_{l}$. Say, $A$ argues for a change in meaning based on some moral considerations while $B$ argues to keep $m_{2}$ based on some other moral reasoning. As before, such quarrels in conceptual ethics are often worth the fight. But now assume that in our particular case, there actually is no moral fact of the matter which meaning option to prefer. The speakers' moral considerations are equally justified, say, and using $e$ to express $m_{1}$ is morally speaking on a par with using $e$ to express $m_{2}$. Discussing the topic of which meaning option should be employed when using $e$ is therefore interestingly pointless. One should either employ $m_{1}$ or $m_{2}$-both options are fine. And neither $A$ nor $B$ goes wrong in thinking that it is morally legitimate to employ their preferred concept when using $e$ (even if both speakers are wrong when seeing their respective option as the better, or the best, moral choice).

As before, these sorts of pointlessness displayed in our two sample cases are closely related to the general idea of substantivity spelled out above. After all, in both sample cases, the meaning options advocated by $A$ and $B-m_{1}$ and $m_{2}$-are equally good in a sense that is relevant to the topic under discussion. Whereas in the first sample case, the options advocated are equally good semantically speaking, in the second case they are morally, though not semantically, on a par. What is more, depending on whether $m_{1}$ or $m_{2}$ is adopted, the speakers' statements either come out true or false.

\subsection{The Independence Thesis Revisited}

As we have seen in the last two subsections, different readings of "equally good" give rise to an abundance of different notions of substantivity that help to stay clear on various important theoretical options. 5.2 distinguished between two different notions of verbalness, which relate to merely verbal disputes on the one hand and to metalinguistic disputes on the other. These two types of disputes can share the feature that disputants use one or more key expression(s) differently, making each of their statements come out true in their individual languages. What is more, just like merely verbal disputes, metalinguistic disputes might also be pointless if the negotiated meaning options are relevantly on a par. Having various different notions of substantivity at our disposal provides ways to relate such pointlessness to a 'lack of substantivity'.

When we revisit the phenomenon of merely verbal disputes in this light, we can identify a similar pattern that seems to once again put the independence thesis in 
trouble. Not only is there a subclass of merely verbal disputes in which the propositions communicated by the speakers are true, but we can also find cases in which the 'different languages' which the disputants are speaking (to again adopt Hirsch's terminology) are equally good in some interesting sense of this phrase. So, as in the case of metalinguistic disputes, we can identify a subclass of merely verbal disputes which are closely entangled with some lack of substantivity. It is this subclass, I contend, that Hirsch (2011) has in mind when he classifies the dispute between endurantists and perdurantists as 'merely verbal'. Let me explain.

According to Hirsch, endurantists and perdurantists are speaking so-called "alternative languages": roughly, if one party shifts from its own language (usage of words) to the other party's language, "nothing is gained or lost", according to Hirsch (2011, p. 224). Members of each party can continue to "express all of the (objectlevel) propositions they believe while asserting only sentences that proponents of the other position would assert" (2011, p. 224). On Hirsch's account, the interlocutors' languages are intertranslatable in the sense that for any sentence of one language we can find a sentence in the other language that has the same truth-conditions ("where two sentences have the same truth conditions if, relative to any context of utterance, they hold true with respect to the same possible situations" (2011, p. 77). So, on his account, the different languages are relevantly on a par, i.e. equally good. Even if only endurantists are speaking plain English, according to Hirsch, both parties' languages are alternative languages that have the same Kaplanian character (see e.g. 2011 , p. 232) and are equally able to describe reality as it is. ${ }^{18}$

Secondly, we can be confident that endurantists and perdurantists are also intending to communicate something true with their conflicting utterances. (On Hirsch's account, such confidence is grounded in charity considerations related to principles like charity to understanding or charity to retraction.) And, thirdly, endurantists as well as perdurantists should also concede that the other party is speaking the truth in its own language. The endurantists' and perdurantists' ontological dispute about the existence of temporal parts is therefore merely verbal, according to Hirsch. It is "merely a matter of choosing a language" (2011, p. 288), a dispute in which "nothing [is] substantively at stake beyond the correct usage of language", as Hirsch (2011, p. 144) puts it.

Admittedly, these alleged three features of the endurantists and perdurantists' dispute might be particularly pertinent to philosophical debates. However, they are not features of merely verbal disputes in general. According to Hirsch, the endurantists and perdurantists are merely talking past each other due to their divergent usages of

\footnotetext{
18 Are these languages equally joint-carving in Sider's sense? Sider (2011, p. 175) seems to think that this is what Hirsch has in mind, though he also notes that Hirsch never speaks of "eligibility" or "joint-carvingness" in his work. However, in his reply to Sider (2011), Hirsch (2011, pp. 126-8) emphasises that both of the speakers' languages should certainly be possible, even if Sider is right and the quantifier(-like) expressions in only one of the two languages carve the world's logical joints. According to Hirsch, there is no reason to suppose that eligibility somehow trumps use/charity in this case. (See also (2011, p. 79) for Hirsch's sceptical view on structured and unstructured facts.).
} 
certain expressions (such as "exists"). ${ }^{19}$ But not all merely verbal disputes are like theirs. For not only are there merely verbal disputes in which disputants are intending to convey propositions that they merely take to be true. (See Vermeulen (2018, pp. 336-7) for an example.) But there are also merely verbal disputes in which (i) both disputants are speaking plain English (in cases of ambiguity, for instance) and, most importantly, in which (ii) their languages are not alternative languages in Hirsch's sense.

Hence, as I see it, Hirsch isn't after the general phenomenon of mere verbalness when setting up his account. He is interested in a particular subclass of what canand, as I would argue, should-be called "merely verbal disputes". That is, Hirsch has a rather restricted notion of mere verbalness in mind. And due to his conception of alternative languages involved, the particular phenomenon picked out by his notion is in fact tightly connected to a metasemantic lack of substantivity.

It is important to be clear what the further examples and considerations of this section amount to. Do they really spell trouble for the independence thesis advocated in the first part of this paper? In a way, yes. As we have seen, there are in fact prominent readings of "verbalness" and "verbal dispute" which render the independence thesis false. (And this is something Balcerak Jackson (2014) seems to pass over.) These readings focus on disputes in which disputants are using alternative (i.e. equally good) languages. The sentences uttered thus come out as nonsubstantive in a legitimate sense of this term, if they are true in one of the disputants' languages but false in the language of the other speaker. Furthermore, "verbal dispute" can also refer to metalinguistic disputes in which there is no fact of the matter which disputant is correct. The languages which the speakers are advocating in these cases are equally good in some relevant respect(s), too. On these notions of verbalness then, there is in fact a close connection between verbalness and nonsubstantivity-also evidentially speaking. For judging a dispute to be (merely) verbal in this sense just means judging the sentences uttered to be nonsubstantive.

However, as others have made clear, such readings of "verbalness" are in fact quite narrow. In particular, notions like Hirsch's are not suited to capture the general phenomenon of speakers talking past each other, as is the focus of theorists like Balcerak Jackson, Jenkins or Vermeulen. Instead, these notions pick out notable subclasses of verbal disputes in which the uttered sentences are interestingly nonsubstantive. There is nothing in the nature of verbalness and nonsubstantivity broadly construed, however, which would logically connect these phenomena. It is thus important to emphasise that the rationale behind this section does not undermine but rather complements the results of earlier sections.

Of course, whether to take verbal disputes and nonsubstantivity as two independent phenomena eventually also comes down to 'mere' questions of terminology. Given the plurality of notions of substantivity and verbalness in the philosophical landscape, it seems advisable to acknowledge some basic distinctions in order to better systematise the existing conceptual disarray. For a start, theorists should refrain from implicitly using terms like "(merely) verbal" and "nonsubstantive"

\footnotetext{
19 Note that this does not mean that there is nothing left for endurantists and perdurantists to disagree about. In particular, they can still have a metalinguistic dispute about which of their two divergent uses of language is best. See e.g. Belleri (2017) on this.
} 
interchangeably. Otherwise, crucial distinctions laid out in this paper are likely to be overlooked. Moreover, the distinction between merely verbal disputes on the one hand and metalinguistic disputes on the other should also be reflected in the terminology used. Are the speakers merely talking past each other? Or is their dispute supposed to be covertly about language and involves genuine disagreement? As these two phenomena are importantly different, it seems advisable to let this difference be reflected in one's terminology. Thirdly, it is important to note that more specific notions of verbalness are available and already part of philosophers' conceptual toolboxes. Some of these notions - and Hirsch's prominent notion of mere verbalness in particular-essentially relate to some interesting concepts of nonsubstantivity. Detailing these more specific notions of verbalness seems crucial for a better understanding of philosophers' ambitions (and how to criticise them). The developed idea of relativising substantivity to different standards of evaluations, that gives rise to various more specified notions of substantivity (including Sider's), provides further conceptual resources to tackle this task.

The following flow chart, displaying some of the relations developed in this paper, might help to survey parts of the wide conceptual landscape. ${ }^{20}$

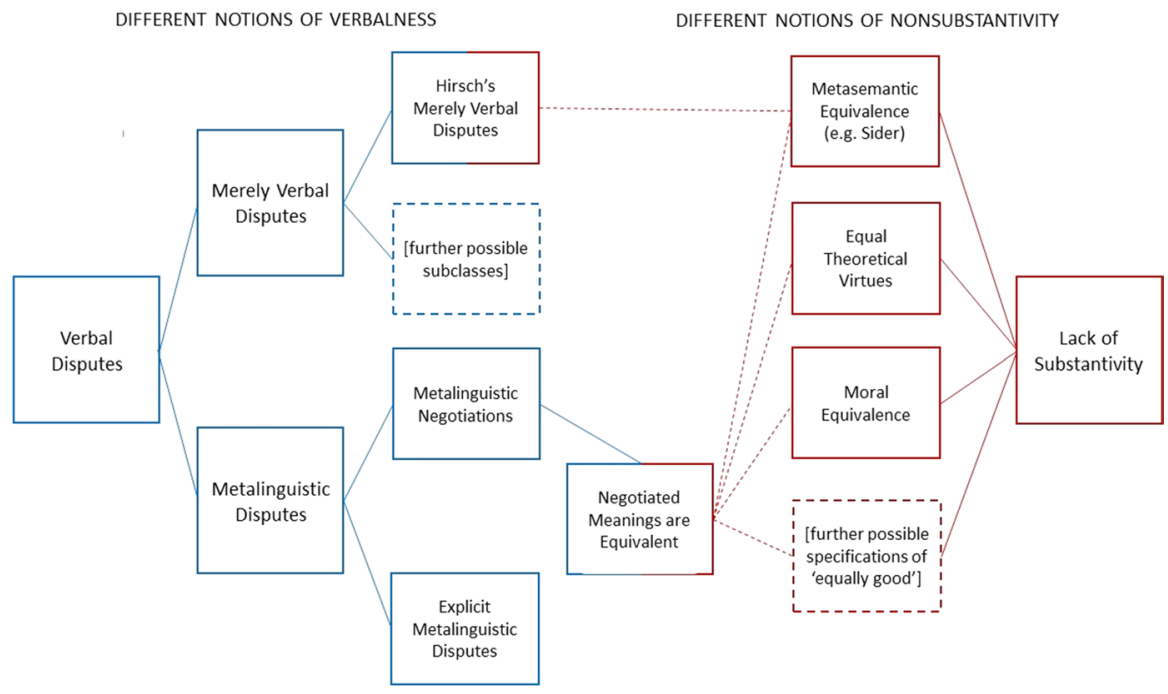

\footnotetext{
${ }^{20}$ Note that the notions of SMubstantivity and spurious substantivity, that I introduced in Sect. 4 with regard to the generalised metasemantic notion of substantivity, can in principle also be mapped on to the many other existing notions of substantivity displayed (see 5.1). To avoid overcomplicating the chart, however, I have left the generalised ideas of SMubstantivity and spurious substantivity out of the picture.
} 


\section{Conclusion}

When properly discussing the independence and interdependence of verbalness and nonsubstantivity, there certainly are 'mere' questions of terminology involved. These terminological questions, however, are in urgent need of answers. Verbal disputes are of utmost interest to philosophers. Allegations of "mere verbalness" against philosophical debates are serious and severe. Philosophers should therefore choose their terminology carefully when discussing these phenomena or when raising such allegations (but not all theorists do so). This paper has presented various novel conceptions and distinctions which should be taken into consideration when coming up with claims of "mere verbalness" and "(non)substantivity". Furthermore, it has clarified and explained how the various phenomena picked out by these terms interrelate.

The first part of the paper was concerned with a general understanding of mere verbalness according to which speakers in a merely verbal dispute are simply talking past each other. As Sects. 1, 2, 3 laid out, this phenomenon is logically independent from a metasemantic lack of substantivity construed along the lines set out by Sider (2011). Section 4 then raised a problem for the presented notion of nonsubstantivity and its advocated independence of mere verbalness. The problem could be answered by bringing novel notions of SMubstantivity and spurious substantivity into play. Section 5 finally presented a variety of related concepts of verbalness and nonsubstantivity. The section once again generalised the metasemantic understanding of substantivity developed in Sect. 2. And it introduced various possibilities to specify the very basic idea on which Sider's account is grounded. That gave rise to many workable notions of substantivity. Additionally, Sect. 5 distinguished between two importantly different classes of verbal disputes and pointed to cases of metalinguistic negotiations in which the sentences uttered are relevantly nonsubstantive. Moreover, it was acknowledged that there also exist restricted notions of mere verbalness which are essentially related to disputants speaking equally good languages. As we have seen, on Hirsch's particular reading of "mere verbalness", merely verbal disputes and nonsubstantivity do in fact come out as two sides of the same coin.

Summing up, "(merely) verbal dispute" and "lack of substantivity" relate to a large number of considerably different notions. An important aim of this paper was to explore the conceptual landscape and systematise the existing terminological disarray. Whether verbalness and nonsubstantivity are really independent of each other ultimately depends on which of the many notions of mere verbalness and substantivity are employed. For some prominent understandings of "verbalness" and "nonsubstantivity", however, the independence thesis still stands.

Acknowledgements For helpful discussion, I would like to thank members of the $\mathrm{PhD}$ colloquium in Hamburg as well as members of colloquia in Berlin and Bonn. I am grateful to two anonymous reviewers of this journal whose insightful comments really helped me to improve the paper. Many thanks to an anonymous reviewer of another journal, too, and to Moritz Schulz and Julia Zakkou for their support.

Funding Open Access funding enabled and organized by Projekt DEAL. 
Open Access This article is licensed under a Creative Commons Attribution 4.0 International License, which permits use, sharing, adaptation, distribution and reproduction in any medium or format, as long as you give appropriate credit to the original author(s) and the source, provide a link to the Creative Commons licence, and indicate if changes were made. The images or other third party material in this article are included in the article's Creative Commons licence, unless indicated otherwise in a credit line to the material. If material is not included in the article's Creative Commons licence and your intended use is not permitted by statutory regulation or exceeds the permitted use, you will need to obtain permission directly from the copyright holder. To view a copy of this licence, visit http://creativecommons.org/licen ses/by/4.0/.

\section{References}

Balcerak Jackson, B. (2013). Metaphysics, verbal disputes and the limits of charity. Philosophy and Phenomenological Research, 86, 412-434.

Balcerak Jackson, B. (2014). Verbal disputes and substantiveness. Erkenntnis, 79, 31-54.

Belleri, D. (2017). Verbalism and metalinguistic negotiation in ontological disputes. Philosophical Studies, 174, 2211-2226.

Belleri, D. (2018). Two species of merely verbal disputes. Metaphilosophy, 49, 691-710.

Burge, T. (1979). Individualism and the mental. Midwest Studies in Philosophy, 4, 73-121.

Cappelen, H., \& Hawthorne, J. (2009). Relativism and monadic truth. OUP.

Chalmers, D. (2011). Verbal Disputes. Philosophical Review, 120, 515-566.

Davidson, D. (1974). Belief and the basis of meaning. Synthese, 27, 309-323.

Grice, P. (1957). Meaning. The Philosophical Review, 66, 377-388.

Grice, P. (1969). Utterer's meaning and intention. The Philosophical Review, 78, 147-177.

Hirsch, E. (2011). Quantifier variance and realism - essays in metaontology. OUP.

Jenkins, C. S. I. (2014). Merely verbal disputes. Erkenntnis, 79, 11-30.

Kripke, S. (1980). Naming and necessity. Harvard University Press.

Lewis, D. (1983). New Work for a Theory of Universals. Australasian Journal of Philosophy, 61, 343-377.

MacFarlane, J. (2014). Assessment sensitivity - relative truth and its applications. OUP.

Plunkett, D. (2015). Which concepts should we use?: Metalinguistic negotiations and the methodology of philosophy. Inquiry, 58, 828-874.

Plunkett, D., \& Sundell, T. (2013). Disagreement and the Semantics of Normative and Evaluative Terms. Philosophers' Imprint, 13, 1-37.

Prinzing, M. (2018). The revisionist's rubric: Conceptual engineering and the discontinuity objection. Inquiry, 61, 854-880.

Sidelle, A. (2007). The method of verbal dispute. Philosophical Topics, 35, 83-113.

Sider, T. (2011). Writing the book of the world. OUP.

Sider, T. (2017). Substantivity in feminist metaphysics. Philosophical Studies, 174, 2467-2478.

Speaks, J. (2018). Theories of meaning. In Zalta, E. (Ed.) The stanford encyclopedia of philosophy (Winter 2018 Edition). Retrived from, https://plato.stanford.edu/archives/win2018/entries/meaning.

Thomasson, A. (2015). Ontology made Easy. OUP.

Thomasson, A. (2020). A pragmatic method for normative conceptual work. In A. Burgess, H. Cappelen, \& D. Plunkett (Eds.), Conceptual engineering and conceptual ethics (pp. 435-458). OUP.

Vermeulen, I. (2018). Verbal disputes and the varieties of verbalness. Erkenntnis, 83, 331-348.

Publisher's Note Springer Nature remains neutral with regard to jurisdictional claims in published maps and institutional affiliations. 